\title{
Spatial and Temporal Characteristics of Precipitation in Yungui Plateau during 1961-2015
}

\author{
Wu Jianfeng ${ }^{1,2}$, Yu Luqin ${ }^{1}$, Cao Guangjie ${ }^{1}$, LI Wei ${ }^{3}$ \\ ${ }^{1}$ School of Geography and Tourism, Guizhou Education University, Guiyang 550018, China; \\ ${ }^{2}$ Guizhou Provincial Key Laboratory of Geographic State Monitoring, Guiyang 550018, China; \\ ${ }^{3}$ Institute of Mountain Resource, Guizhou Academy of Sciences, Guiyang 550001, China;
}

\begin{abstract}
In this paper, the daily precipitation data of 19 meteorological stations in Guizhou Province from 1961 to 2015 are used. Using GIS spatial analysis method and linear trend analysis method, the distribution characteristics of annual and seasonal precipitation in Guizhou province were analyzed from space and time. The results show that: (1) From the perspective of spatial distribution, annual precipitation is generally less in the south and north and less in the east and west. The precipitation in winter and spring is east-west distribution and decreases from east to west in the four seasons. The precipitation in summer is roughly north-south and south-north less. The precipitation in autumn is mainly concentrated in southwest Guizhou and Chishui valley. (2) From the time distribution point of view, the precipitation in Guizhou Province showed a general downward trend, of which the precipitation in spring, autumn and winter showed a decreasing trend, the downward trend in autumn was more obvious, and the precipitation in summer increased but not obviously.
\end{abstract}

\section{Introduction}

Precipitation is an important element that reflects the climatic characteristics of a region and is an important climatic factor affecting or reflecting the ecological environment ${ }^{[1]}$. With the development of science and technology, people's requirements for meteorological services are increasing year by year. Research on the spatial distribution of precipitation must be intensive and meticulous in order to meet the needs of modern society ${ }^{[2]}$. Therefore, it is more and more urgent to evaluate and predict long-term precipitation characteristics ${ }^{[3]}$.

Most foreign experts and scholars believe that the average precipitation in the world and the northern hemisphere is a periodical change, but the trend of change in each stage is different. Hulme study shows that between 1950 and 1980, there was no significant decrease in the global average precipitation and a significant decrease in precipitation after the $1990 \mathrm{~s}^{[4]}$. Vinnikov's study of precipitation in different regions of the Northern Hemisphere shows that precipitation increased by nearly $6 \%$ in the mid-latitudes of the Northern Hemisphere from the early 19th century to the $1990 \mathrm{~s}^{[5]}$.Kattsov proposed that the precipitation in the northern hemisphere mid-latitudes has been increasing strongly since the $1920 \mathrm{~s}^{[6]}$. Diaz et al. Obtained the study on the precipitation in the southern hemisphere, and the trend of precipitation in the mid-high latitudes and low latitudes showed consistent ${ }^{[7]}$. Zuo Hongchao et al. Conducted a study on the precipitation in our country, showing that the regional average precipitation characteristics are obvious and the trend of change is not obvious $^{[8]}$; Wang Yanjiao et al. The regional precipitation and decadal variation characteristics of precipitation in China during 1960-2010 show the precipitation There are obvious stages of change ${ }^{[9]}$; Li Yonghua et al. Analyzed the spatio-temporal features of the summer precipitation in the eastern part of Southwest China. The summer precipitation in the eastern part of Southwest China is mainly consistent with the whole region, and the frequency of occurrence is above $60 \%{ }^{[10]}$.

In recent years, although some scholars have done some research on precipitation in Guizhou Province, the characteristics analysis of precipitation in Guizhou Province in time and space is still relatively weak. Therefore, by applying the daily precipitation data of Guizhou Province in recent 55 years, the paper analyzes the precipitation characteristics of Guizhou Province in recent years by using ArcGIS technology and linear trend analysis method from different time scales and spatial analysis.

\section{Study Area Overview}

*Corresponding author: ${ }^{\mathrm{a}} w u j i a n f e n g 74623 @$ sina.com; ${ }^{\mathrm{b}} 110695145 @ q q . c o m ;{ }^{c}$ caoguangjie@gznc.edu.cn; d624360114@163.com; 
Guizhou Province is located in the southwestern part of China and is located in the southeast of the Qinghai-Tibet Plateau. It is a part of the Yunnan-Guizhou Plateau with an average elevation of about $1,100 \mathrm{~m}$. It belongs to a subtropical monsoon climate and is humid and humid throughout the year with an average annual temperature of about $15-18^{\circ} \mathrm{C}^{[11]}$. The terrain is high in the west and low in the east, with complex and diverse topography. $90 \%$ of the area is mountainous and hilly, with $73 \%$ of the area being karst.

\section{Research Data and Methods}

\subsection{Data and Processing}

In this paper, the daily precipitation data of 19 meteorological stations in Guizhou province for 1962-2015 years are selected as the research data, and the data are derived from the China Meteorological Data Network (http://data.cma.cn). The quarterly and annual precipitation data used in this study are calculated by accumulating daily precipitation.

\subsection{Research Methods}

\subsubsection{Linear trend method}

The linear trend analysis refers to the use of $n$ to express the sample size, the time is expressed in $\mathrm{t}_{i}$, the precipitation variable is expressed by $x_{i}$, and the linear regression equation between $x_{i}$ and $\mathrm{t}_{i}$ is established.

$$
\hat{x_{i}}=a+b t_{i} \quad(i=1,2, \ldots n)
$$

In the upper form, the precipitation factor is expressed by $x$, the $a$ is the regression constant, the $b$ indicates the regression coefficient and the $t$ represents the time [10].

\subsubsection{Kriging}

Kriging is one of the most commonly used spatial interpolation methods, the general formula is as follows:

$$
\hat{Z}\left(x_{0}\right)=\sum_{i=1}^{n} \lambda_{i} z\left(x_{i}\right)
$$

Among them: $\mathrm{z}=\left(x_{i}\right)$ the observations, they are located in the region $x_{i}$ position; $\mathrm{x}_{0}$ is the observed point to be estimated; $\lambda_{i}$ is the weighted coefficient; $n$ is the total number of known observation points ${ }^{[12]}$.

\section{Results and Analysis}

\subsection{Precipitation spatial distribution}

\subsubsection{Spatial distribution of annual precipitation}

Guizhou precipitation affected by topography, topography, altitude, slope and other factors. Precipitation performance of more than North South, East and West less. Among them, the precipitation in the eastern part of Tongren region, the southwestern part of Southeast Guizhou, the eastern part of Qiannan, most of Anshun and most of southwestern Guizhou are more than those of the other regions, and the average annual precipitation is basically above $1200 \mathrm{~mm}$; In Bijie region, southern Zunyi, the average annual rainfall is not higher than $1000 \mathrm{~mm}$ (Figure 1).

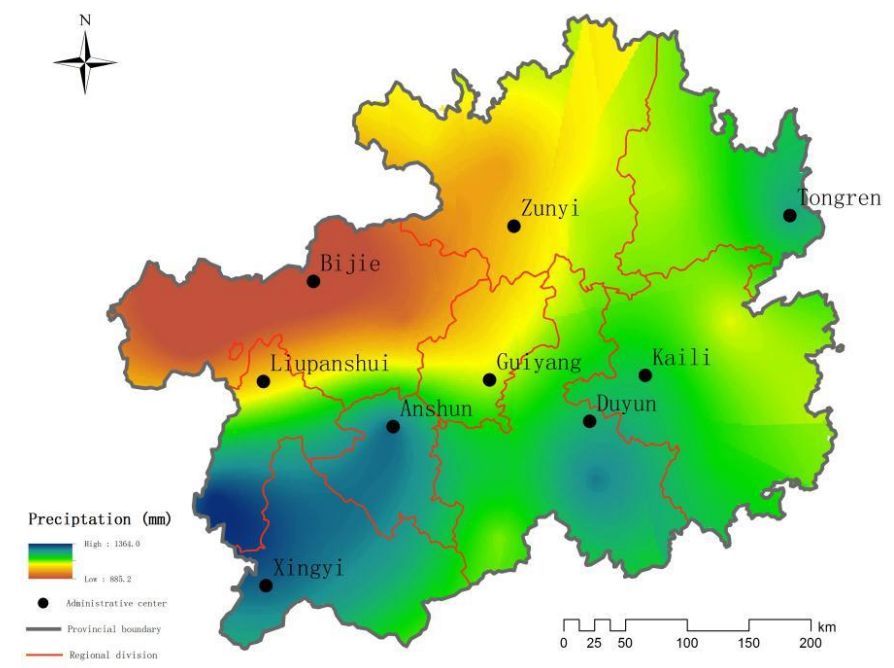

Figure 1 1961-2015 year average annual precipitation distribution map of Guizhou

\subsubsection{Seasonal precipitation distribution}

On the whole, the precipitation in spring decreased gradually from east to west, and the precipitation was more in the eastern part of Tongren, the eastern part of Guizhou Province and the southern part of Guizhou
Province, with the precipitation reaching $390 \mathrm{~mm}$. The second part was the west of Tongren, the eastern part of Zunyi, Anshun And western Qiannan, the average precipitation is $360.3 \mathrm{~mm}$; the average precipitation in western Zunyi, Guiyang and western Guizhou is $311.0 \mathrm{~mm}$; in Bijie area, the average precipitation is only 


\section{1mm(Figure 2 (a)).}

Summer is the year with the heaviest precipitation, which is affected by the summer monsoon from the Indian Ocean and the warm and humid currents over the Pacific Ocean, plus the uplift of the Yunnan-Guizhou Plateau. Precipitation changes roughly north-south, of which precipitation is mainly concentrated in Anshun, southern Liupanshui, most of Qianxinan, the average precipitation is $701.4 \mathrm{~mm}$. Followed by Qiannan Prefecture and Qiandongnan Prefecture. The average precipitation is $540.9 \mathrm{~mm}$. The less precipitation is the northern part of Bijie, the southwest part of Zunyi and the eastern part of Qiandongnan. The average precipitation is $456.1 \mathrm{~mm}$ (Figure $2(\mathrm{~b})$ ).

In the fall, precipitation rose from Siberia cold air and the Yunnan-Guizhou Plateau to the area north of Guiyang, except for the precipitation in the Chishui River

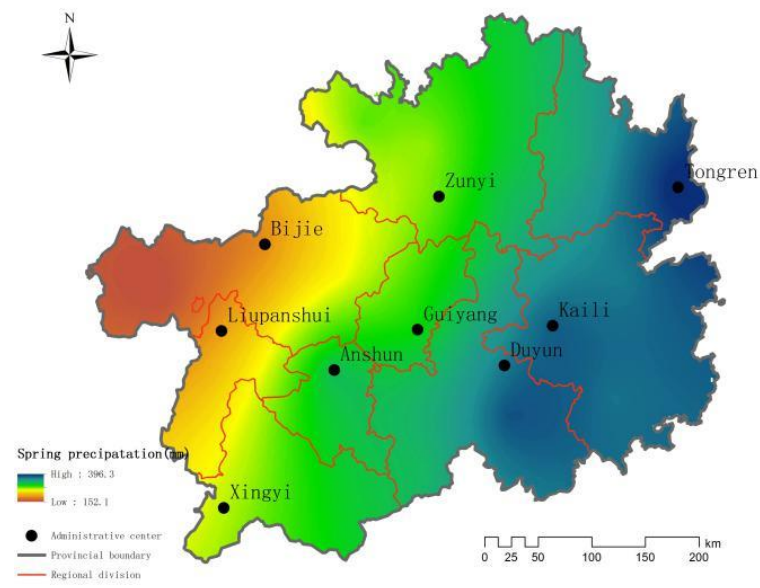

(a)Spring

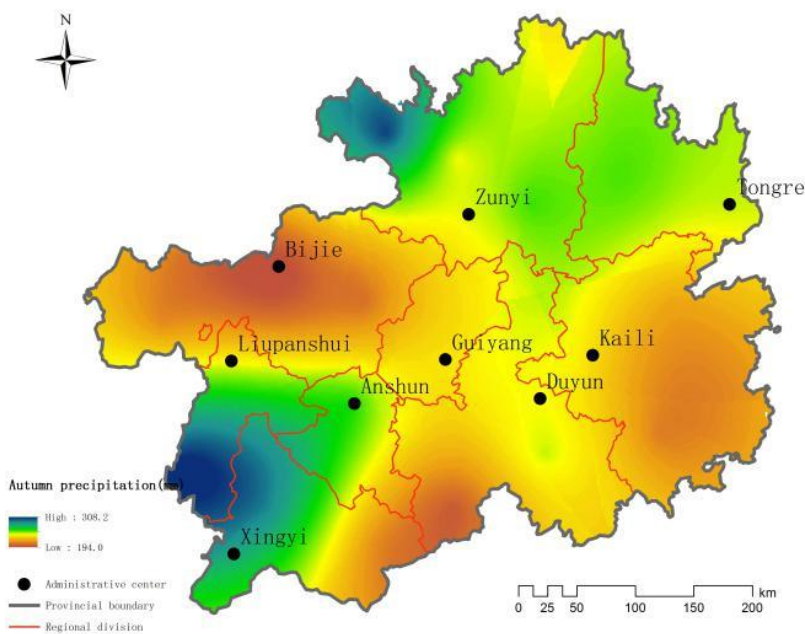

(c)Autumn with more precipitation $(297.9 \mathrm{~mm})$, the precipitation decreased from north to south, southwestern Qianxinan Prefecture and southern Liupanshui The precipitation in the vast area is relatively concentrated. Precipitation is relatively small areas: most of Bijie area, southwest of Qiannan, and the eastern part of Qiandongnan(Figure 2 (c)).

East and West less precipitation in winter, something significant difference. Affected by the south cold air is relatively large, Tongren southeast of most parts of southeastern Guizhou, Qiannan Prefecture, more precipitation, the average rainfall of $104 \mathrm{~mm}$; precipitation in the central region of Guizhou in less than $65.86 \mathrm{~mm}$; Bijie more Less, the average precipitation is less than $50 \mathrm{~mm}$, at least Weining area, only $29.89 \mathrm{~mm}$ (Figure 2 (d)).

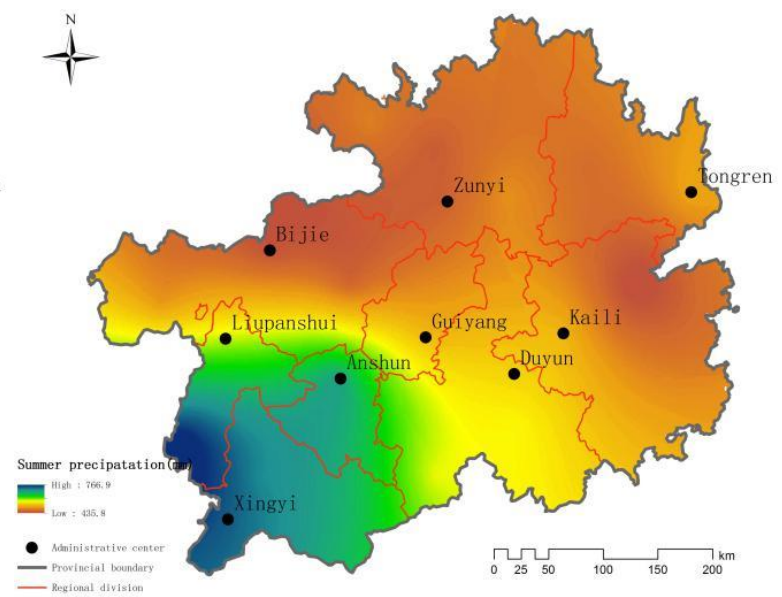

(b)Summer

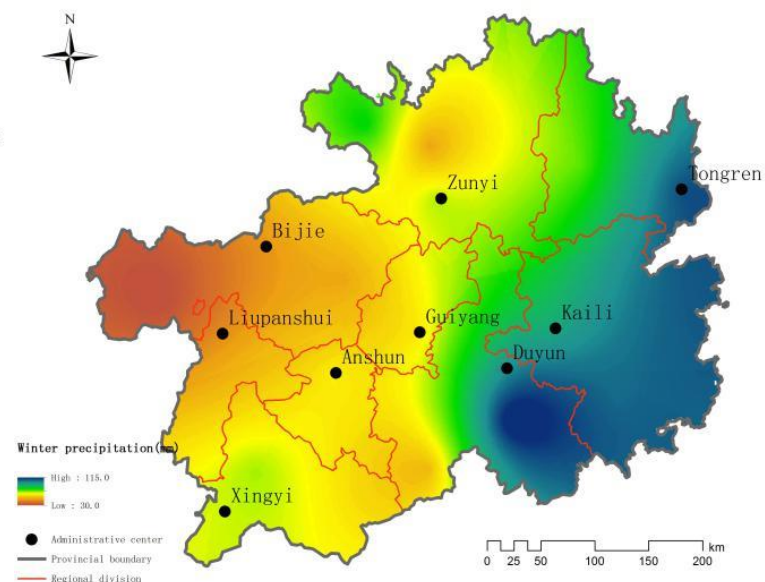

(d)Winter

Figure 2 The spatial distribution of seasonal precipitation in Guizhou in the past 1961-2015 years

\subsection{Analysis of time trend characteristics of precipitation}

\subsubsection{Characteristics of annual precipitation time}

From the linear trend, the trend of annual precipitation in Guizhou province is decreasing with the tendency of
$14.18 \mathrm{~mm} / 10 \mathrm{a}$. From the 5 year moving average precipitation can be seen in the past 55 years, precipitation of Guizhou province from 1961 to 1980, volatility is not, in 1980 to 1990 between the annual precipitation decreased significantly, from 1991 to 2000 completed a reduction by increasing from 2001 to 2015, precipitation showed a decreasing trend. From the numerical point of view, the annual average precipitation 
in Guizhou province is $1147.2 \mathrm{~mm}$ in 1961 2015. The year with more rainfall is 1967 , the annual precipitation is as high as $1357 \mathrm{~mm}$, followed by 2014 , nearly $1340 \mathrm{~mm}$.
The lowest annual precipitation appears in 2011, only $818.2 \mathrm{~mm}$, and the annual precipitation is the largest and the least year is $538.8 \mathrm{~mm}$ (Figure 3).

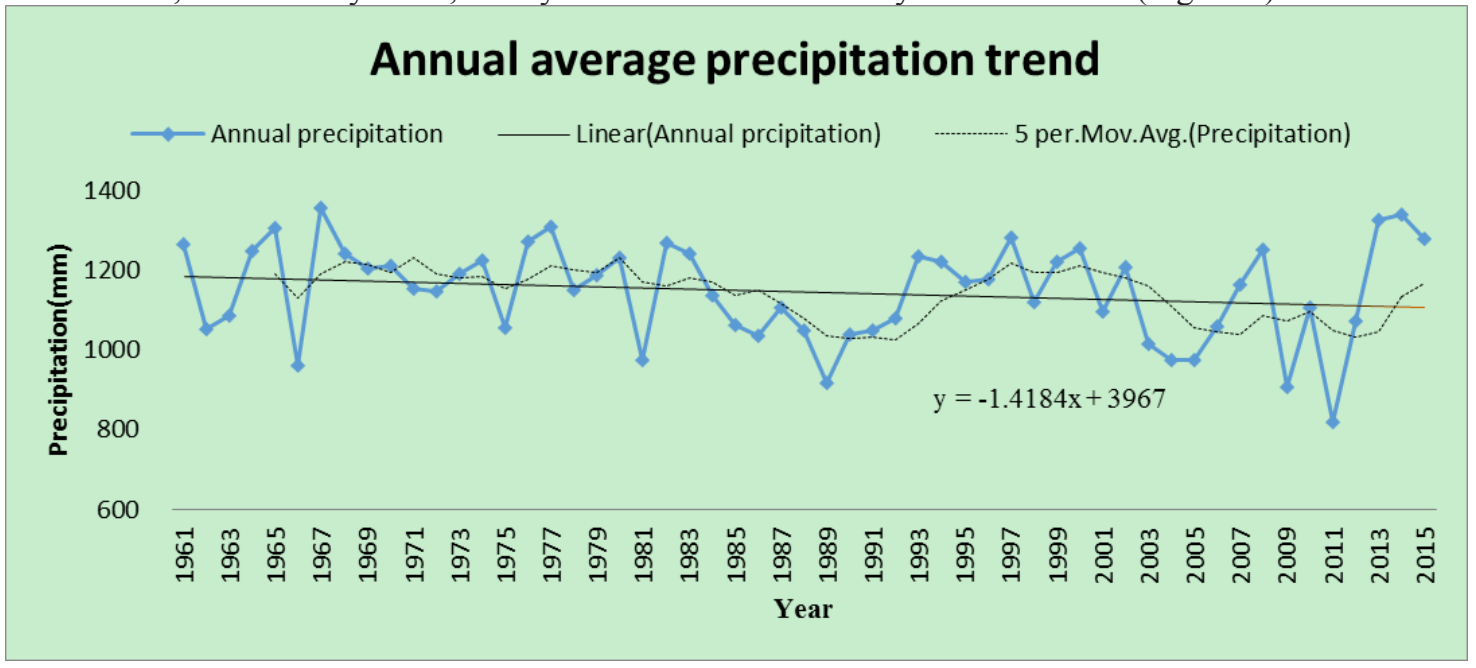

Figure 3 Change trend of annual precipitation in Guizhou province 1961 2015

\subsubsection{Seasonal distribution of precipitation}

The study area obtained by the seasonal variation trend of precipitation can be (Figure omitted), summer precipitation in Guizhou province has increased a weak trend, increasing the size of $4.0 \mathrm{~mm} / 10 \mathrm{a}$; in the spring and autumn winter three season precipitation showed a downward trend, the average rainfall in the three quarter decreased in size respectively is $6.4 \mathrm{~mm} / 10 \mathrm{a}, 10.9 \mathrm{~mm} / 10 \mathrm{a}$, $1.7 \mathrm{~mm} / 10 \mathrm{a}$.In addition, according to the 5-year sliding average of the seasonal precipitation:

The average precipitation in spring shows a continuous increase trend from 1961 to 1975; there is a decreasing trend from 1976 to 1990; among them, the decrease extent is the most obvious since 1980. Statistics show that precipitation in 1980 than in 1991 decreased by $106.5 \mathrm{~mm}$.

Summer precipitation showed a decreasing trend from 1961 to 1967; Precipitation increased steadily from 1967 to 1971; Precipitation decreased obviously from 1971 to 1977; Precipitation changed little from 1978 to 1986 ; Precipitation decreased from 1992 to 2001. From 1992 to 2001, a small precipitation peak appeared. However, precipitation tends to decrease from 2006 to 2015. Overall, summer precipitation in Guizhou Province has been on the rise for the past 55 years.

Precipitation decreased from 1961 to 1971 in autumn; slightly increased from 1972 to 1983; declined again from 1982 to 1992; precipitation increased from 1992 to 2001; from 2001 to 2015 The annual precipitation slowly recovered from its lowest level in 55 years.

There are three small peaks and three small tumbles in winter, with the three small peaks appearing in 1971-1976, 1983-1985 and 1993-1998 respectively. Three minor ebb occurred in 1961-1971, 1976-1983 and 1985-1992, respectively. However, the precipitation has been decreasing from 1996 to 2012, with a slight increase but not significant from now to 2013.

\section{Conclusion}

Based on the daily precipitation data from 1961 to 2015 in Guizhou Province combined with ArcGIS spatial analysis method and linear trend analysis method, this study analyzed the precipitation characteristics of Guizhou Province in recent 55 years and reached the following conclusions:

(1) Spatial distribution: The average annual precipitation in Guizhou Province has been mostly distributed in the south and the north less and east and west less in 55 years, of which the annual average precipitation is more than $1100 \mathrm{~mm}$. The precipitation in the four seasons has obvious difference. The precipitation in winter and spring is less in the east and west, and the precipitation is decreasing from east to west, of which the precipitation in winter is the least, the summer is less than the north and the south is mainly concentrated in the southwest of Guizhou, In the most seasons, the precipitation in autumn is mainly concentrated in the southwest of Qianxinan Prefecture and the southern part of Liupanshui. The areas with less precipitation distribute in the Bijie area and the southwest of Qiannan.

(2)The time trend: Guizhou province 55 years precipitation overall downward trend. During the year, the seasonal variation of precipitation is large, and the precipitation in spring, autumn and winter has a significant downward trend, especially in autumn precipitation.

\section{Acknowledgments}

Guizhou provincial education department natural science foundation "Multi - source Remote Sensing Information Characteristics Analysis of Impervious Surfaces in Karst Watershed (QJHKY[2017]206)"; Guizhou province science and technology project "Poverty Evolution in Extremely Poverty Peaks and Poduks and Its 
Man-Ground Relationship Response (QKHJ[2018]1123)”; National natural science foundation "The Coupling Mechanism of Population - settlement and Ecology in Typical Rural Areas of Karst Mountains and Its Optimization And Control Mode (41461041)” ; Guizhou province brainstorm project of social development project

"Mechanism and Risk Assessment and Early Warning Study of Guizhou Flood and Drought Disaster in Changing Environment (QKH [2016] 2845)” .

\section{References}

1. Jin L Y, Fu J L, Chen F H. Over the past 44 years, Chinese northwest Precipitation Regional Difference and the impacts of global warming on the [J]. Geography Science, 2005:567-572.

2. Sun Q, Zhou S Q, Kang N, et al. GIS based precipitation analysis of the upper and middle upper reaches of the Yangtze River [J]. Journal of Nanjing Meteorological Institute, 2007,30 (2): 201-209.

3. Guizhou Meteorological Bureau. Guizhou short term weather forecast Handbook [M], Guizhou: Meteorology Press, 1987:369- 4761.

4. Hulme.M,R.Marsh,P.D.Jones. Global changes in a humidity index between 1931-1960 and 1961-1990[J].Climate Res.1992(2):1-22.

5. Vinnikov.K.Y,P.Y.Groisman,K.M.Lugina.Empirical data on contemporary climate chang-es(temperature and precipitation)[J].J.Climate.1990(3):662-677.

6. Kattsov.V,J.E.Walsh.Twentieth-century trends of Arctic precipitation from observationaldata and a climate model simulation[J].J.Climate.2000,13(4):1362-1370.

7. Diaz,H.F,R.s.Bradley,J.K.Eischeid.Precipitation fluction over global land areas since the late 1800's[J].J.Geophys.Res.1989(94):1195-1210.

8. Zuo H C, Lv S H, Hu Y Q. The change trend of temperature and precipitation in recent 50 years Chinese analysis [J]. Plateau Meteorology, 2004,23 (2): 238-244.

9. Wang Y J, Yan F.1960-2010 Precipitation Regional Differentiation and interdecadal changes in China, [J]. geo scientific progress, 2014,33 (10): 1354-1363.

10. Li Y H, Xu H M, Bai Yingying and so on. The spatial and temporal characteristics of summer precipitation in the eastern part of the southwest China are [J]. Plateau Meteorology, 2010, 29 (2): 523-530.

11. Yang R F. The existing problems and Development Countermeasures for the utilization of water resources in Guizhou province [J]. Henan water conservancy and south to North Water Transfer, 2013,57 (16): 19-20.

12. Duan J F, Wang Q C, Wang G L,et al. Analysis of spatial interpolation method of precipitation in Yongding River Basin of Shanxi based on GIS; [J]. Shanxi agricultural science, 2010,38 (3): 44-47. 